\title{
Coping Behavior among Mothers Age 35 Years and Over with Unwanted Pregnancy in the Working Area of Kassi-Kassi Health Center Makassar City, Indonesia
}

\author{
Alfiyatussaidah ${ }^{1}$, Sudirman Nasir $^{1}$, Wahiduddin $^{2}$, Suriah $^{1}$, Amran Razak $^{3}$, Agus Bintara $^{4}$ \\ ${ }^{1}$ Department of Health Promotion, Faculty of Public Health, Hasanuddin University, Indonesia \\ ${ }^{2}$ Department of Epidemiology, Faculty of Public Health, Hasanuddin University, Indonesia \\ ${ }^{3}$ Department of Health Administration and Policy, Faculty of Public Health, Hasanuddin \\ University, Indonesia \\ ${ }^{4}$ Department of Environmental Health, Faculty of Public Health, Hasanuddin University, \\ Indonesia
}

\begin{abstract}
An unwanted pregnancy is a high-risk pregnancy that has psychological stress and impacts on nursing behavior during pregnancy. This requires coping efforts in order to handle stress. This study aims to analyze the coping behavior of mothers aged 35 years and over who experience unwanted pregnancies. This research is a qualitative research with a phenomenological approach. Data were obtained by means of in-depth interviews, focus group discussions and participatory observation on 21 informants consisting of pregnant women, families, health workers, and Posbunda cadres. Content analysis is used to identify topics or categories in data. The results showed that to overcome the problem two coping behaviors were carried out, namely coping focusing on emotions and coping focusing on problems. Coping behavior focuses on emotions, including praying, sleeping, sitting quietly outside the house, drinking coffee excessively, and getting fresh air. The coping behavior that focuses on the problem is telling the problem to find a solution and the consumption of herbs, soda, and drugs to abort the pregnancy. To support coping efforts, pregnant women get support from family, neighbors, friends, health workers, and Posbunda cadres. It is suggested to the Kassi-Kassi Health Center Makassar City to hold an intensive counseling program and health education regarding the correct use of contraceptive tools and methods to prevent unwanted pregnancies.
\end{abstract}

Keywords: Unwanted Pregnancy, Coping, Behavior, Problems, Health

Received: October 17, 2020

Revised: October 29, 2020

Accepted: November 7, 2020

\section{Introduction}

Unwanted pregnancy is one of the major public health problems around the world (Sedgh et. al., 2014). According to the World Health Organization (WHO), 74 million women experience unwanted pregnancies, both in low and middle income countries (WHO, 2019). The Indonesian Demographic and Health Survey (IDHS) shows that unwanted pregnancy occurs mostly among women who have more than 3 children, are more than 35 years old, are in urban areas, and have access to health services (IDHS, 2017). In addition, about 50\% of cases of unwanted pregnancy occur due to contraceptive failure (Winner et al., 2012).

Pregnancy at the age of 35 years and over is at risk of disrupting the mother's health due to declining conditions. Pregnant women at old age are more likely to have children with disabilities, bleeding, and complications during pregnancy and childbirth. In addition, mothers with unwanted pregnancies are under psychological pressure because they think about their age, economic burden 
and how to undergo childcare in the future. This then has an impact on unhealthy pregnancy care behavior among mothers (Erol, 2010; Goossens, 2016; Akbarzadeh, et. al, 2016, \& Kaimudin, 2018). The existence of a coping strategy is very important and needed in the psychological adjustment of pregnant women to the anxiety and stress experienced during pregnancy (Khavari et al., 2018).

To deal with stress, individuals try to solve problems by eliminating stressors or regulating their emotions to adjust to the impact that stressful conditions or situations will cause (Agustiningsih, 2019). Coping is an individual effort to overcome various demands or face various changing conditions both internally and externally by managing cognition and behavior. Pregnant women can use this strategy as a prevention against more severe levels of anxiety (Rabia et al., 2017).

The coping effectiveness of pregnant women can be influenced by the support they get. The support provided, especially from the family, namely the husband can contribute in helping to deal with maternal stress during pregnancy (Guardino \& Schetter, 2015). In addition, unwanted pregnancy has different behavioral implications for each pregnant woman depending on the choice of coping strategies and social support received. Knowledge, experience, and emotional intelligence can also influence one's coping strategies (Erözkan, 2013). Therefore, it is important to analyze the reasons behind the mother's coping behavior during unwanted pregnancy.

Based on an initial interview with health workers at the Kassi-Kassi Health Center in Makassar City, Indonesia (SA, 36 years old), information was obtained that unwanted pregnancy occurs because the mother has failed the contraceptive method. Unpreparedness to accept pregnancy conditions because pregnant women already have many children, a history of diseases such as hypertension, and fear of the risk of pregnancy complications in old age. Kassi-Kassi Health Center also had the highest number of pregnancy complication cases, namely 342 cases with the most incidence occurring in pregnant women over 35 years of age (Kassi-Kassi Health Center, December 2019). Based on these problems, the researcher was interested in examining the coping behavior carried out by women aged 35 years and over who experienced unwanted pregnancies in the working area of the Kassi-Kassi Health Center, Makassar City, Indonesia.

\section{Methods}

This type of research is a qualitative research with a phenomenological approach. This research was conducted in the working area of Kassi-Kassi Health Center in Makassar City, South Sulawesi, Indonesia. Participants were selected via purposive sampling. The informants in this study were pregnant women aged 35 years and over with unwanted pregnancies, families of pregnant women, health workers, and Posbunda cadres.

Qualitative data were collected using in-depth interviews, focus group discussions, and participatory observation. Analysis of the data used in this research is content analysis which is a way to find the meaning of written or visual material by way of systematic content allocation to the detailed categories by dividing the data into small pieces and then coding each part and then gathering the coding into similar and calculated groups.

\section{Results and Discussion}

\section{Coping behavior for maternal problems with unwanted pregnancies}

In dealing with problems or stress during unwanted pregnancy, the informants did coping. There are two types of coping, namely coping behavior that focuses on emotions and coping behavior that focuses on problems. This type of coping behavior focuses on emotions between praying, sleeping, sitting quietly outside the house, seeking fresh air, drinking excessive coffee. 
"... Pray a lot when praying. Usually I pray there, what is it like, there is a kind of calm feeling. I'm pregnant like this, I'm not young anymore. I do realize that I have to remember, because age who knows. Nothing, except Allah alone ... " (SSI, IW, 38 years)

“... I increase my sleep time more. Day or night. Because when I sleep there is nothing else I think about... " (SSI, FW, 37 years)

“... Sitting quietly outside the house. There I used to be alone. It's also normal if I want to go outside, I always make coffee first. I bring (coffee) to the front, drink it while sitting. With that, my mind will calm down ... " (SSI, SS, 41 years)

"... I used to go to the front of the house. I work randomly, as well as traveling to get fresh air. Instead of being here, at home, it just makes me dizzy ..." (SSI, RI, 37 years)

Meanwhile, the type of coping behavior that focused on the problem was carried out by the informant, namely telling the problem to find a solution and efforts to abort by drinking herbs, soda, and abortion drugs.

"... If there is a problem, I tell my husband. I then talked about my problem, because I can't stress myself ... " (SSI, MN, 41 years)

"... How many times did I drink herbal medicine. My friend said this could abort. But after I drank, there was no change ... " (SSI, FW, 37 years)

“... I drank this a lot. Honestly, maybe I was a sinner, because I am currently pregnant, I have taken one complete pill. After that, I drink more soda every morning or dawn. At night one big bottle of soda ... that's what I drink every night. It's like one week after that I found out (pregnant), I drank it all. Because I don't want to get pregnant anymore. I also used gastrul, which cost one hundred thousand and one to get out anyway. But still remains (fetus). Whereas usually people go out right away, whereas I don't. I don't know why, let me do it, work hard or take medicine, it doesn't come out either. Still surviving this (fetus) and now making me tortured ... " (SSI, SS, 41 years)

Some of the impacts were felt by informants after engaging in coping behavior. The impact of coping behavior is divided into positive impacts and negative impacts. The positive impact that was mostly expressed by the informants was a sense of calm and reduced mental burden.

“... I feel calm when I tell my husband. Including praying too, that's all that makes me feel calm. It's because all my complaints have been conveyed ... " (SSI, NW, 45 years)

“...The burden felt less after I poured out the problem. We give each other advice, friends here, neighbors also want to help each other. So my life feels calmer... " (SSI, MN, 41 years)

Meanwhile, the most negative impacts felt by the informants were back and stomach pain. This occurs due to frequent consumption of drugs and herbs that can abort the womb.

“... Often this hurts behind me. Here (back) it feels like it's going to be cut off. Recently, my lower stomach also hurts ... " (SSI, SS, 41 years)

“... I don't think she wants to abort her own child, instead she just makes herself suffer. Because after she drank the herbal medicine, there she also started complaining that her stomach hurt ... " (SF, 39 years, Family of pregnant women) 


\section{Social support of mothers with unwanted pregnancies}

The form of support received by the informants varied. Based on the results of in-depth interviews, generally the greatest support received by informants came from families, namely husbands and parents. In addition, other sources of support are neighbors, friends, health workers, and Posbunda cadres (community health cadres). Overall, the most informants received support from their families.

“... My husband really loves me, so he supports me. As usual he helped me with housework. In fact, he told me not to work hard ... "(SSI, MN, 41 years)

"...My mother. She is helping me here, please accompany me to check my health condition. In fact, she wants to take care of my child when it's born ... "(SSI, FW, 37 years)

Other support was expressed by the informants, which came from neighbors and friends who provided psychological support. This is stated in the following expression:

"... If my neighbor is here, it's like family. She used to tell stories about experiences, she also listened to me confide in, then we gave each other input. Like so ... "(SSI, MN, 41 years)

In addition, social support also comes from health workers (midwife) and community health cadres or cadres called Posbunda. The following is an excerpt from the interview:

“... That day I was afraid because I was still receiving treatment, and it turned out that I was pregnant again. The midwife told me to stay healthy. After that she checked me with medicine and she gave it to me "(SSI, MN, 41 years)

This information is in line with that obtained from in-depth interviews, FGDs and observations of health workers and Posbunda cadres.

"... We support it, we support it by continuing to monitor the pregnant woman during each examination. Especially mothers who are over 35 years of age are at risk. We also provide counseling so that mothers always maintain their health, especially their psychology. Given a suggestion for mothers who no longer want to have children to use long-term contraceptive methods or MKJP. This is so that the pregnancy she doesn't want doesn't happen again in the future ... "(SA, 36 years, Health workers)

"...Many things. We Posbunda cadres always socialize what must be done, give advice, and direct the midwives to be diligent in checking. Get ready between them iffor example there are complaints. We tell them to come quickly to the health workers if there are complaints. So we always anticipate them, guard them until the delivery day ... "(FGD, KS, 48 years, Posbunda cadre)

Some informants did not receive social support at all. Among the support that was not received the most was the availability of costs for daily needs.

"... I want my husband to continue working, not at home. So that he can get money to buy for our daily needs ... " (SSI, SS, 41 years)

\section{Coping behavior for maternal problems with unwanted pregnancies}

The results showed that there were 2 coping behaviors performed by women aged 35 years and over to overcome the problem of unwanted pregnancy, namely emotional focused coping and problem focused coping. 
In general, informants in this study used coping that focused on emotion. This is because they involve more efforts to regulate their emotions about the problems at hand, such as praying (positive reappraisal), sleeping and drinking coffee excessively (escape avoidance), sitting quietly outside the house (self controlling), and looking for fresh air (distancing). This coping behavior is considered useful for calming the mind and eliminating the informants anxiety about the problems they are experiencing.

Singer J's research (2004) obtained information that pregnant women who are experiencing emotional situations overcome their problems by exploring themselves for things that are soothing and far from feeling anxious. In line with this study, research by (Dibaba et al., 2013; Mohammadi et al., 2015; Akbarzadeh et al., 2016) also found the same thing that when mothers find out about their pregnancy, they are then filled with many thoughts such as old age and financial problems which ultimately make pregnant women respond with panic, cry, worry, and other anxious feelings.

The next coping behavior that the informants also did was religious coping, namely praying (positive reappraisal). This religious coping behavior is considered to be able to help informants deal with the pressure they experience because they feel they feel calm. According to Kasberger (2002) \& Rammohan et al., (2002) religion has an important role in managing stress, religion can provide individuals with direction / guidance, support, and hope, as well as emotional support. Through prayer, rituals and religious beliefs can help a person in coping when experiencing stress in life, because of hope and comfort. Participants also expressed religious coping strategies in (Izugbara \& Egesa, 2014; Mohammadi et al., 2015; Akbarzadeh et al., 2016).

Some informants in this study also used coping to focus on problems. This is because the informant wants to eliminate situations that cause problems or find solutions to solve problems. The coping behavior focuses on the problems carried out by the informants, namely seeking social support by telling stories and telling problems to their husbands to find solutions (planful problem solving), and drinking herbs, soda, and coping confrontative drugs.

Informants also conducted coping behavior in seeking social support in research conducted by Dibaba, et. al (2013); Mohammadi, et. al (2015); Shahry, et. al (2016); \& Kusuma (2018). In some of these studies, informants revealed that when faced with problems, pregnant women will try to find and get support from people around them. Family support, especially couples, really helps pregnant women get through tough times.

In addition to seeking social support, coping behavior focuses on the problem the informant is doing, namely confrontational coping. Informants who are very depressed about the problems they are experiencing make aggressive and risky problem solving efforts. The types of confrontational coping performed by pregnant women in this study were consuming herbs, soda, and drugs to abort the content (coping confrontative).

In line with this study, in the research of Ramírez-Zetina et al., (2000) and O'hara (2009) stated that one of the symptoms of depression in the perinatal period, such as chaotic thoughts and sometimes accompanied by hallucinations in the form of the idea of injuring the fetus. In an unwanted pregnancy, the mother is faced with several risks such as lack of care during pregnancy, malnutrition, taking drugs to abort, stress and mental stress, etc.

There are 2 impacts of coping behavior by informants, namely positive impacts and negative impacts. The positive impact is felt, namely a sense of calm and reduced thought burden. Murzaeni (2018) revealed that pregnant women make efforts to overcome their anxiety because they get emotional comfort. The negative impact felt by the informants was pain in the back and stomach. In line with this study, Dibaba, et. al (2013) and Akbarzadeh, et. al, (2016) revealed that some 
pregnant women with depressed psychological conditions will think of taking actions that hurt themselves, such as taking drugs that eventually put themselves in a sick stomach and risk of disruption to the fetus due to potential teratogenic exposure (developmental disorders in the fetus).

\section{Social support of mothers with unwanted pregnancies}

Social support is the most effective way that a person can use to adjust to difficult and stressful events (Kim et al., 2008). In this study, informants received social support from family, neighbors, friends, health workers, and Posbunda cadres. The form of support you get from the family is help with household maintenance, caring to ask how you are doing, and always being accompanied during pregnancy checks.

Several studies from Beck \& Driscoll (2006); Stone \& Menken (2008); Klainin \& Arthur (2009); Fitelson et al (2010). reported that the factor that most causes depression during the perinatal period is the lack of social support from husbands and other loved ones. For this reason, the role and involvement of family members, especially husbands, need to be increased because the family is the main source of support for pregnant women so that mothers are able to adapt to their pregnancies so that mothers do not experience psychological problems.

In addition, social support is also obtained from neighbors and friends, namely in the form of psychological support such as being listened to when venturing and providing suggestions for routine health checks. Most of the informants in this study were also Posbunda cadres. Other forms of support were also obtained by informants from health center health workers, namely health examination services, psychological support in the form of positive suggestions, and administration of drugs (vitamins). Rabiah (2017) reveals that social support is a strategy to overcome the negative effects that are most sought after by pregnant women, by sharing stories with husbands, friends, or health workers enough to calm the heart and reduce worry about the condition of their pregnancy.

Even though most of them had received social support, some informants admitted that they did not receive any support at all, such as expenses for daily needs. In line with this research, AndajaniSutjahjo et al (2007); Mohammadi, et al (2015); Akbarzadeh et al (2016); Abame, et al (2018) reported that economic problems such as poverty and insufficient family income are a concern in the family because they contribute to maternal emotional changes during pregnancy to domestic conflicts. Leahy-Warren et al (2012) also stated in his research that lack of or no social support can affect the role of mothers in managing the household and caring for children, and can endanger the health of mothers and babies.

\section{Conclusion}

Coping strategies undertaken to overcome stress problems in unwanted pregnancy are emotionalfocused coping and problem-focused coping. Emotion-focused coping forms in this study were praying, sleeping, sitting quietly outside the house, drinking coffee excessively, and getting fresh air. Meanwhile, coping focuses on the problem that is done is to seek social support by telling stories and telling problems to the husband and confrontational coping, namely consuming herbs, soda, and drugs to abort the pregnancy. To support coping efforts, mothers aged 35 years and over who experience unwanted pregnancies get support from family, neighbors, friends, health workers, and Posbunda cadres.

\section{References}

Abame, D. E., Abera, M., Tesfay, A., Yohannes, Y., Ermias, D., Markos, T., \& Goba, G. (2019). Relationship between unintended pregnancy and antenatal care use during pregnancy in Hadiya Zone, Southern Ethiopia. Journal of reproduction \& infertility, 20(1), 42. 
Agustiningsih, N. (2019). Gambaran Stress Akademik dan Strategi Koping Pada Mahasiswa Keperawatan. Jurnal Ners dan Kebidanan (Journal of Ners and Midwifery), 6(2), 241-250.

Akbarzadeh, M., Yazdanpanahi, Z., Zarshenas, L., \& Sharif, F. (2016). The women's perceptions about unwanted pregnancy: A qualitative study in Iran. Global journal of health science, 8(5), 189.

Andajani-Sutjahjo, S., Manderson, L., \& Astbury, J. (2007). Complex emotions, complex problems: understanding the experiences of perinatal depression among new mothers in urban Indonesia. Culture, medicine and psychiatry, 31(1), 101-122.

Beck. C.T., \& Driscoll, J.W. (2006). Postparum Mood and Anxiety Disorder: A Clinician's Guide. Canada: Jones and Bartlett

Dibaba, Y., Fantahun, M., \& Hindin, M. J. (2013). The association of unwanted pregnancy and social support with depressive symptoms in pregnancy: evidence from rural Southwestern Ethiopia. BMC pregnancy and childbirth, 13(1), 135.

Erol, N., Durusoy, R., Ergin, I., Döner, B., \& Çiçeklioğlu, M. (2010). Unintended pregnancy and prenatal care: A study from a maternity hospital in Turkey. The European Journal of Contraception \& Reproductive Health Care, 15(4), 290-300.

Erözkan, A. (2013). Exploring the relationship between perceived emotional intelligence and coping skills of undergraduate students. Journal of Human Sciences, 10(1), 15371549.

Fitelson, E., Kim, S., Baker, A. S., \& Leight, K. (2011). Treatment of postpartum depression: clinical, psychological and pharmacological options. International journal of women's health, 3,1 .

Goossens, J., Van Den Branden, Y., Van der Sluys, L., Delbaere, I., Van Hecke, A., Verhaeghe, S., \& Beeckman, D. (2016). The prevalence of unplanned pregnancy ending in birth, associated factors, and health outcomes. Human Reproduction, 1-13.

Guardino, C., \& Schetter, CD. (2015). Coping During Pregnancy: A Systematic Review and Recommendations Department of Psychology. Los Angeles USA: University of California

IDHS. (2017). The Indonesian Demographic and Health Survey. Jakarta: BKKBN, BPS, Ministry of Health, and ICF International.

Izugbara, C., \& Egesa, C. (2014). The management of unwanted pregnancy among women in Nairobi, Kenya. International Journal of Sexual Health, 26(2), 100-112.

Kaimmudin, L., Pangemanan, D., \& Bidjuni, H. (2018). Hubungan usia ibu saat hamil dengan kejadian hipertensi di RSU Gmim Pancaran Kasih Manado. Jurnal Keperawatan, 6(1).

Kasberger, E. R. (2002). A correlational study of post-divorce adjustment and religious coping strategies in young adults of divorced families. In Second Annual. Undergraduate Research Symposium CHARIS Institute of Wisconsin Lutheran College. Milwaukee, WI (Vol. 53226).

Khavari, F., Golmakani, N., Saki, A., \& Aghamohammadian Serbaf, H. (2018). The Relationship between Prenatal Coping Strategies and Irrational Beliefs in Pregnant Woman. Journal of Midwifery and Reproductive Health, 6(2), 1215-1222. 
Kim, H. S., Sherman, D. K., \& Taylor, S. E. (2008). Culture and social support. American psychologist, 63(6), 518.

Klainin, P., \& Arthur, D. G. (2009). Postpartum depression in Asian cultures: a literature review. International journal of nursing studies, 46(10), 1355-1373.

Kusuma, R. (2018). Hubungan Pengetahuan Dan Sikap Ibu Hamil Tentang Antenatal Care Dengan Kunjungan K4. Jurnal Psikologi Jambi, 3(1), 24-24.

Leahy-Warren, P., McCarthy, G., \& Corcoran, P. (2012). First-time mothers: social support, maternal parental self-efficacy and postnatal depression. Journal of clinical nursing, 21(3-4), 388-397.

Mohammadi, E., Nourizadeh, R., \& Simbar, M. (2015). Iranian Azeri women's perceptions of unintended pregnancy: A qualitative study. Iranian journal of nursing and midwifery research, 20(2), 255.

Murzaeni, I. (2018). Hubungan Strategi Coping Dengan Kecemasan Pada Ibu Hamil Yang Mengalami Anemia (Studi di Wilayah Kerja Puskesmas Cukir Kabupaten Jombang). Thesis, STIKES Insan Cendeki Medika Jombang.

O'Hara, M. N. (2009). Postpartum Depression: What. Journal of Clinical Psychology, 65, 1258-1269.

Rabia, S., Hakeem, N., \& Aziz, S. (2017). Coping strategies in women with anxiety and depression during prenatal period. Annals Of Abbasi Shaheed Hospital And Karachi Medical \& Dental College, 22(3), 191-199.

Rabiah, H. (2017). Kesejahteraan Subjektif Pada Ibu Primigravida dengan Kehamilan Risiko Tinggi. Program Magister Psikologi: Universitas Muhammadiyah Surakarta

Ramírez-Zetina, M., Richardson, V., Avila, H., Caraveo, V. E., Salomón, R. E., Bacardí, M., \& Jiménez-Cruz, A. (2000). La atención prenatal en la ciudad fronteriza de Tijuana, México. Revista Panamericana de Salud Pública, 7, 97-101.

Rammohan, A., Rao, K., \& Subbakrishna, D. K. (2002). Religious coping and psychological wellbeing in carers of relatives with schizophrenia. Acta Psychiatrica Scandinavica, 105(5), 356-362.

Sedgh, G., Singh, S., \& Hussain, R. (2014). Intended and unintended pregnancies worldwide in 2012 and recent trends. Studies in family planning, 45(3), 301-314.

Shahry, P., Kalhori, S. R. N., Esfandiyari, A., \& Zamani-Alavijeh, F. (2016). A comparative study of perceived social support and self-efficacy among women with wanted and unwanted pregnancy. International journal of community based nursing and midwifery, 4(2), 176.

Singer, J. A. (2004). Narrative identity and meaning making across the adult lifespan: An introduction. Journal of personality, 72(3), 437-460.

Stone, S. D., \& Menken, A. E. (Eds.). (2008). Perinatal and postpartum mood disorders: Perspectives and treatment guide for the health care practitioner. Springer Publishing Company.

WHO. (2019). High rates of Unintended Pregnancies . Linked to Gaps in Family Planning Services: World Health Organization. 
Winner, B., Peipert, J. F., Zhao, Q., Buckel, C., Madden, T., Allsworth, J. E., \& Secura, G. M. (2012). Effectiveness of long-acting reversible contraception. New England Journal of Medicine, 366(21), 1998-2007. 